\title{
POSITRON TOMOGRAPHIC IMAGING OF TUMORS USING MONOCLONAL ANTIBODIES
}

$$
\text { DOE/ER/60789-7 }
$$

Final Progress Report

for the Period April 15, 1989 to October 31, 1995

Michael R. Zalutsky

Duke University Medical Center

Durham, North Carolina 27710

February 1997

Prpared for

THE U.S. DEPARTMENT OF ENERGY

AWARD NUMBER DE-FG-89ER60789

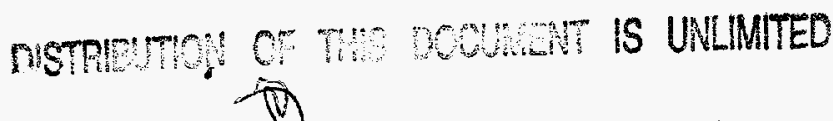




\section{DISCLAJMER}

Portions of this document may be illegible in electronic image products. Images are produced from the best available original document. 


\section{A. SCOPE AND ORIGINAL SPECIFIC AIMS}

The overall objective of this research is to develop methods for utilizing positron emission tomography (PET) to increase the clinical potential of radiolabeled monoclonal antibodies (MAbs). Enhancement of MAb tumor localization by hyperthermia also was proposed. Studies were to have been performed with both ${ }^{18} \mathrm{~F}$ and ${ }^{124} \mathrm{I}$; however, the lack of its availability (until quite recently) prevented experiments with ${ }^{124} \mathrm{I}$. Instead, two additional lines of inquiry were initiated in which we utilized aspects of the radiofluorinaton chemistries originally developed for MAbs for labeling chemotactic peptides and meta-iodobenzylguanidine (MIBG) analogues with ${ }^{18} \mathrm{~F}$. In order to investigate the possibility of combining the imaging advantages and quantitative capabilities inherent in PET with the cellular specificity of MAbs, we proposed the following original specific aims:

1) To develop and optimize methods for labeling MAbs and their fragments with fluorine-18 and iodine-124. Our goals are to maximize yield, minimize synthesis time (particularly for F-18), maintain MAb affinity and immunoreactivity and render the procedure suitable for automation.

2) To examine the tissue distribution of F-18 and I-124 labeled MAbs and fragments in athymic mouse and rat xenograft models. These experiments will provide an indication of stability of label in vivo and whether specific tumor uptake can be achieved in a time compatible with the nuclide half life.

3) To determine the pharmacokinetics of F-18 and I-124 labeled MAbs and fragments in normal dogs using positron emission tomography. In addition to demonstrating the safety of these procedures, these studies will validate the ability of PET to quantify normal organ uptake in dogs by comparison to tissue uptake data obtained from the same animals at necropsy.

4) To examine the tissue distribution of F-18 and I-124 labeled MAbs reactive with canine tumors in pet dogs with spontaneous cancers. MAb concentrations in tumors determined by PET are compared to levels determined by tissue sampling. Initial studies will use TP-3 and TP-1 MAbs directed against canine and human osteogenic sarcoma.

5) To investigate the effect of tumor-localized hyperthermia on the tumor uptake of radiolabeled MAbs and fragments using PET in dogs with spontaneous cancers. Our results in the athymic mouse model indicate that hyperthermia can increase MAb accumulation in tumor by a factor of two. Using PET, we can pursue these investigations in a more realistic model, using each animal as its own control.

\section{B. MAIN RESEARCH ACCOMPLISHMENTS}

1. Development and refinement of $N$-succinimidyl $8-\left[\left(4^{\prime}-\left[{ }^{18} \mathrm{~F}\right]\right.\right.$ fluorobenzyl $)$ amino $]$ suberate 
and $\mathrm{N}$-succinimidyl 4-[ $\left.{ }^{18} \mathrm{~F}\right]$ fluorobenzoate as reagents for labeling $\mathrm{MAb}$ fragments with ${ }^{18} \mathrm{~F}$.

2. The first demonstration that selective and specific tumor localization of ${ }^{18} \mathrm{~F}$-labeled MAb fragments can be achieved in a murine xenograft models in a time frame compatible with the half life of ${ }^{18} \mathrm{~F}$.

3. Definition of ${ }^{18} \mathrm{~F}$-labeled $\mathrm{F}\left(\mathrm{ab}^{\prime}\right)_{2}$ pharmacokinetics in normal dogs, indicating that levels of labeled MAb fragments adequate for PET imaging could be administered to human patients with acceptable radiation dosimetry.

4. Demonstration in dogs with spontaneous tumors that primary and metastatic osteosarcomas can be imaged by PET using ${ }^{18} \mathrm{~F}$-labeled TP-3 Fab fragments.

5. Demonstration that hyperthermia can enhance the delivery of intact MAbs and $F\left(a b^{\prime}\right)_{2}$ fragments to human tumor xenografts and identification of shorter half life radionuclides as most appropriate for this technique.

6. Development of para- $\left[{ }^{18} \mathrm{~F}\right]$ fluorobenzylguanidine, an ${ }^{18} \mathrm{~F}$-labeled analog of MIBG which localizes in normal tissue targets (heart and adrenals) and in a canine pheochromocytoma.

7. Development of radiosynthetic method for 4- $\left[{ }^{18} \mathrm{~F}\right]$ fluoro-3-iodobenzylguanidine and documentation that this compound exhibits identical binding to human neuroblastoma cells as MIBG itself.

8. Identification of the location of lysine residues in the variable regions of MAbs TP-1 and TP-3 and possibly, the first analysis of the implications of this type of data for radiolabeling.

\section{PROGRESS SUMMARY}

\section{Refinement of ${ }^{18}$ F Protein Labeling Methodologies and Evaluation in Athymic Mouse Models}

$N$-succinimidyl 8-[(4'- $I^{18}$ Flfluorobenzyl)amino]suberate (SFBS). A method has been developed for labeling proteins with ${ }^{18} \mathrm{~F}$ which utilizes SFBS as the protein acylation agent. The procedure involves conversion of aqueous $\left[{ }^{18} \mathrm{~F}\right]$ fluoride ion to tetrabutylammonium $\left[{ }^{18} \mathrm{~F}\right]$ fluoride, preparation of $4-\left[{ }^{18} \mathrm{~F}\right]$ fluorobenzonitrile by fluoro for nitro exchange in 4-nitrobenzonitrile, treatment with lithium aluminum hydride to generate $4-\left[{ }^{18} \mathrm{~F}\right]$ fluorobenzylamine and finally, reaction of this intermediate with disuccinimidyl suberate (DSS) to yield SF $\mathrm{SS}$. We have investigated the in vitro and in vivo properties of the $\mathrm{F}\left(\mathrm{ab}^{\prime}\right)_{2}$ fragment of $\mathrm{Mel}-14$, a murine $\operatorname{IgG}_{2 \mathrm{a}}$ which reacts with a chondroitin sulfate proteoglycan present in gliomas and melanomas, after 
labeling using SFBS. This MAb fragment is of interest because of our ongoing clinical radioimmunotherapy trials using ${ }^{131} \mathrm{I}$-labeled Me1-14 $\mathrm{F}\left(\mathrm{ab}^{\prime}\right)_{2}$. All experiments were performed in paired-label format to allow direct comparison of the ${ }^{18} \mathrm{~F}$-labeled $\mathrm{F}\left(\mathrm{ab}^{\prime}\right)_{2}$ with Mel-14 $\mathrm{F}\left(\mathrm{ab}^{\prime}\right)_{2}$ labeled using $N$-succinimidyl 3-[25I]iodobenzoate (SIB). Specific binding was evaluated in vitro with a single-point glioma homogenate assay and biodistribution was investigated in athymic mice with subcutaneous D-54 MG human glioma xenografts.

Since DSS is a homobifunctional cross-linking agent, a key issue was to determine the concentration of DSS which represented the best compromise between maximizing labeling efficiency and minimizing deleterious modifications of the labeled $\mathrm{F}\left(\mathrm{ab}^{\prime}\right)_{2}$. When $250 \mu \mathrm{g}$ of DSS was used and HPLC purification of SFBS was not performed, almost complete conversion of 4$\left[{ }^{18} \mathrm{~F}\right]$ fluorobenzylamine to SFBS was observed; however, the specific binding of the ${ }^{18} \mathrm{~F}$-labeled Me1-14 $\mathrm{F}\left(\mathrm{ab}^{\prime}\right)_{2}$ preparation was low ( $20 \pm 8 \%$ vs. $62 \pm 2 \%$ for SIB control), and tumor localization was poor $(1.9 \pm 0.3 \% \mathrm{ID} / \mathrm{g}$ vs $6.2 \pm 0.6 \%$ for SIB). Decreasing DSS levels to 100 $120 \mu \mathrm{g}$ reduced synthetic yields to $30-35 \%$ but resulted in a dramatic improvement in the in vitro and in vivo behavior of the ${ }^{18} \mathrm{~F}$-labeled Me1-14 $\mathrm{F}\left(\mathrm{ab}^{\prime}\right)_{2}$. Under these conditions, the affinity and specific binding of the ${ }^{18} \mathrm{~F}$-labeled MAb fragment were essentially identical to those observed for Mel-14 labeled with ${ }^{125} \mathrm{I}$. Accumulation of ${ }^{18} \mathrm{~F}$ and ${ }^{125} \mathrm{I}$ in tumor 1-6 hr after injection also was similar. There was an excellent correlation $(r=0.98)$ between the tumor uptake of the two radionuclides, with the slope of the line near unity. This supports the possibility of using a PET scan with ${ }^{18} \mathrm{~F}$-labeled MAb fragment to predict tumor dose for a subsequent therapy with ${ }^{131} \mathrm{I}$ labeled MAb. However, even at 100-120 $\mu \mathrm{g}$ DSS, uptake of ${ }^{18} \mathrm{~F}$ was significantly higher than ${ }^{125} \mathrm{I}$ in some normal tissues, particularly liver and spleen.

Relatively early time points were selected for these biodistribution experiments because of the short half life of ${ }^{18} \mathrm{~F}$; however, under these conditions, it is important to demonstrate that tumor uptake reflects MAb specificity rather than nonspecific accumulation due to blood pool activity. The specificity of ${ }^{18} \mathrm{~F}$-labeled Me1-14 $\mathrm{F}\left(\mathrm{ab}^{\prime}\right)_{2}$ uptake was determined by calculating the localization index. The localization index is defined as the ratio of specific-to-nonspecific MAb fragment in tissue to the simultaneous specific-to-nonspecific MAb fragment uptake ratio in blood. By normalizing all ${ }^{18} \mathrm{~F}$ activities to co-administered ${ }^{125} \mathrm{I}$-labeled Me1-14 $\mathrm{F}\left(\mathrm{ab}^{\prime}\right)_{2}$, the distribution of ${ }^{18} \mathrm{~F}$-labeled Me1-14 $\mathrm{F}\left(\mathrm{ab}^{\prime}\right)_{2}$ could be compared with that of ${ }^{18} \mathrm{~F}$-labeled nonspecific RPC $5 \mathrm{~F}\left(\mathrm{ab}^{\prime}\right)_{2}$. The localization index in tumor was $3.7 \pm 1.3 \mathrm{at} 4 \mathrm{hr}$ and $6.9 \pm 1.9 \mathrm{at} 6 \mathrm{hr}$, while in normal tissues, localization indices of about 1 were calculated. These results indicate that the uptake of ${ }^{18} \mathrm{~F}$-labeled Me1-14 $\mathrm{F}\left(\mathrm{ab}^{\prime}\right)_{2}$ in subcutaneous D-54 MG xenografts is specific.

$N$-succinimidyl 4-II Flfluorobenzoate (SFB). The usefulness of ${ }^{18} \mathrm{~F}$-labeled MAb PET data for predicting dosimetry depends on the extent to which its tissue distribution mimics that obtained with the therapeutic radionuclide. As noted above, increased accumulation of ${ }^{18} \mathrm{~F}$ was observed in the liver and spleen when Mel-14 F $\left.(\mathrm{ab})_{2}\right)_{2}$ was labeled using SFBS. Since encouraging results have been obtained with SIB and $\left[{ }^{211} A t\right]$ astatobenzoyl MAb conjugates in animal models, a method for coupling $\left[{ }^{18} \mathrm{~F}\right]$ fluorobenzoyl groups to MAbs could be an attractive alternative to SFBS. Unlike the case with ${ }^{131} \mathrm{I}$ and ${ }^{211} \mathrm{At}$, an electrophilic destannylation reaction 
can not be used with ${ }^{18} \mathrm{~F}$ because the specific activity of electrophilic fluorinating agents derived from $\left[{ }^{18} \mathrm{~F}\right] \mathrm{F}_{2}$ would be too low for labeling MAbs without affecting immunoreactivity. Our alternative method for the synthesis of $N$-succinimidyl $4-\left[{ }^{18} \mathrm{~F}\right]$ fluorobenzoate (SFB) involves three steps; $\left[{ }^{18} \mathrm{~F}\right]$ fluoride for trimethyl-ammonium substitution on 4-formyl $N, N, N$ -

trimethylanilinium triflate, oxidation to $4-\left[{ }^{18} \mathrm{~F}\right]$ fluorobenzoic acid, followed by reaction with $\mathrm{N}$ hydroxysuccinimide and dicyclohexylcarbodiimide to yield SFB. The overall radiochemical yield for SFB is $25 \%$ in a total synthesis and purification time of about $100 \mathrm{~min}$.

In order to determine the suitability of SFB for MAb applications, Mel-14 F(ab') was labeled by reaction with SFB and its in vitro and in vivo properties compared to $\left.\mathrm{F}(\mathrm{ab})_{2}\right)_{2}$ labeled with ${ }^{125}$ I using SIB. Since SFB has the fluorine in the 4 position, the 4 -substituted SIB analogue was used in these experiments. Specific in vitro binding of ${ }^{18} \mathrm{~F}$ - and ${ }^{125} \mathrm{I}$-labeled Me1-14 F(ab') to tumor homogenates was not significantly different $\left({ }^{18} \mathrm{~F}, 58 \pm 3 \% ;{ }^{125} \mathrm{I}, 62 \pm 2 \%\right)$ and the affinity constants for binding to the human glioma D-247 MG line also were similar $\left\{{ }^{18} \mathrm{~F},(6.7 \pm\right.$ 1.1) $\left.\times 10^{8} \mathrm{M}^{-1} ;{ }^{125} \mathrm{I},(8.0 \pm 0.6) \times 10^{8} \mathrm{M}^{-1}\right\}$. Initially, the biodistribution of the two radiohalogenated $\mathrm{F}\left(\mathrm{ab}^{\prime}\right)_{2}$ fragments were compared using paired-label protocols in normal mice. In contrast to the studies described above comparing SFBS and SIB, levels of both radionuclides in normal tissue were quite similar. For example, liver uptake at $2 \mathrm{hr}$ was $5.4 \pm 0.7 \% \mathrm{ID} / \mathrm{g}$ for ${ }^{18} \mathrm{~F}$ compared with $6.0 \pm 0.8 \% \mathrm{ID} / \mathrm{g}$ for ${ }^{125} \mathrm{I}$; in other tissues, such as the spleen, blood, lungs, heart and muscle, no significant difference between ${ }^{18} \mathrm{~F}$ and ${ }^{125} \mathrm{I}$ accumulation was observed.

Further comparisons of ${ }^{18} \mathrm{~F}$ - and ${ }^{125} \mathrm{I}$-labeled Me1-14 $\mathrm{F}\left(\mathrm{ab}^{\prime}\right)_{2}$ were performed in athymic mice with D-54 MG human glioma xenografts. In the first experiment, the mean tumor weight was $0.27 \pm 0.04 \mathrm{~g}$ and in the second, $1.03 \pm 0.30 \mathrm{~g}$. Tumor accumulation of ${ }^{18} \mathrm{~F}$ and ${ }^{125} \mathrm{I}$ increased with time in both studies. Tumor levels after one half life of ${ }^{18} \mathrm{~F}$ were $59-77 \%$ of those reached at $6 \mathrm{hr}$. In the experiment using smaller tumors, tumor uptake of ${ }^{18} \mathrm{~F}$ was $18.8 \pm 3.0 \% \mathrm{ID} / \mathrm{g}$ at $6 \mathrm{hr}$ compared with $22.3 \pm 3.7 \% \mathrm{ID} / \mathrm{g}$ for ${ }^{125} \mathrm{I}$. As expected, tumor accumulation was lower in the groups with larger tumors; however, ${ }^{18} \mathrm{~F}$ and ${ }^{125} \mathrm{I}$ levels again were quite similar, with differences of only $6-19 \%$ observed between the two radionuclides. The selectivity of tumor uptake was evaluated by calculating tumor-to-normal-tissue ratios. Tumor-to-normal-tissue ratios for ${ }^{18} \mathrm{~F}$ and ${ }^{125}$ I generally were nearly identical. Exceptions were tumor-to-liver and tumor-to-intestine ratios at 2-6 hr, which were significantly higher $(P<0.05$, paired $t$-test $)$, and tumor-to-kidney ratios at 1-4 hr, which were significantly lower $(P<0.05)$ for ${ }^{18} \mathrm{~F}$-labeled Me1-14 $\mathrm{F}\left(\mathrm{ab}^{\prime}\right)_{2}$. These results suggest that $\mathrm{PET}$ imaging of tumors may be possible in patients using MAb fragments labeled with ${ }^{18} \mathrm{~F}$ using SFB.

The SFB method offers several advantages for labeling proteins with ${ }^{18} \mathrm{~F}$ which have led to our selection of this method for the experiments which have been proposed in this grant application. First, it yields a labeled template that is structurally analogous to iodo- and astatobenzoates which have been developed for the radioiodination and astatination of MAbs. Second, MAb fragments labeled using SFB exhibit better tumor-to-normal tissue ratios as a consequence of lower normal tissue uptake. And third, particularly for small MAb fragments such as SFv MAb and peptides, the lack of the 8-carbon spacer present in SFBS should facilitate 
labeling with minimal modification in biophysical properties. However, labeling proteins with $\mathrm{SFB}$ requires a longer preparation time than desirable for routine use with ${ }^{18} \mathrm{~F}$.

To circumvent this problem, we have developed an improved method for the synthesis of SFB that has reduced total synthesis time by about 45 minutes. A reaction time of 5-8 min (versus $25 \mathrm{~min}$ for the original procedure) was sufficient for formation of $4-\left[{ }^{18} \mathrm{~F}\right]$ fluorobenzaldehyde in high yield. In the original method, 30-35 min was necessary to convert $4-\left[{ }^{18} \mathrm{~F}\right]$ fluorobenzoic acid to SFB by reaction with dicyclohexylcarbodiimide and $N$-hydroxysuccinimide. When $N, N^{\prime}$-disuccinimidyl carbonate was used, facile conversion of 4-fluorobenzoic acid to SFB was seen at the micromolar level; however, with ${ }^{18} \mathrm{~F}$, no product was formed at room temperature. Heating at $150^{\circ} \mathrm{C}$ gave SFB in more than $80 \%$ yield in only $1-3$ minutes. Largely as a result of the considerable reduction in total labeling time, these modifications have increased the amount of ${ }^{18} \mathrm{~F}$-labeled $\mathrm{MAb}$ fragment available per $100 \mathrm{mCi}$ of $\left[{ }^{18} \mathrm{~F}\right]$ fluoride by $30-35 \%$.

Purification of SFB using HPLC required an additional 15-20 min preparation time, decreasing available activity; however, this step is recommended for several reasons. Use of crude SFB, or SFB purified using a silica solid phase cartridge, resulted in low protein coupling yields. With Me1-14 F( $\left.\mathrm{ab}^{\prime}\right)_{2}$, SFB conjugation efficiencies were $51 \pm 6 \%$ using HPLC-purified reagent compared with $27 \pm 17 \%$ for crude SFB. Furthermore, 10-15\% protein cross-linking was observed for MAb labeled using crude $\mathrm{SFB}$, presumably due to unreacted $N, N$-disuccinimidyl carbonate. Finally, the immunoreactivity of Me1-14 $\mathrm{F}\left(\mathrm{ab}^{\prime}\right)_{2}$ was decreased by almost a factor of two when HPLC purification of SFB was omitted.

\section{Evaluation of ${ }^{18} \mathrm{~F}$-labeled MAb Fragments in Dogs}

Evaluation of F-18 Labeled Antimyosin MAb Fragments in a Canine Myocardial Infarct Model. In myocardial infarction, intracellular myosin is leaked into the extracellular space and is accessible to serum-bourne agents. Antimyosin MAb fragments labeled with a positron-emitting nuclide might permit the simultaneous exploitation of antimyosin uptake specificity in damaged myocardium and of imaging advantages and quantitative capabilities inherent in PET. Using the [F-18]SFBS method described above, the $\mathrm{F}\left(\mathrm{ab}^{\prime}\right)_{2}$ and Fab fragments of antimyosin were labeled with F-18 and studied in an acute canine myocardial infarct model. Two dogs were studied with the $\mathrm{F}\left(\mathrm{ab}^{\prime}\right)_{2}$ fragment and 4 dogs were studied with the faster clearing Fab fragment. Our objectives were a) to demonstrate that a MAb labeled with F-18 could localize selectively in antigen-rich tissue and $b$ ) to begin to evaluate whether F-18 antimyosin might be of value for the evaluation of myocardial infarction using PET.

Dogs were anesthetized and the left circumflex coronary artery was occluded for $2-3 \mathrm{hr}$. The occlusion was then released to permit reperfusion and $1-5 \mathrm{mCi}$ of the $\mathrm{F}-18$ labeled $\mathrm{MAb}$ fragment was injected 15-60 min later. Serial PET images were then obtained for 2 to $5 \mathrm{hr}$. Tissue distribution studies were performed on Dogs 1-5 in order to determine whether preferential uptake of F-18 labeled MAb fragments in damaged myocardium could be achieved 
in a time frame compatible with the short half life of F-18. Normal, border and ischemic regions were determined using triphenyltetrazulium chloride and multiple samples obtained for F-18 counting.

The highest level of F-18 accumulation in infarcted tissue was achieved in animals (Dogs 3 and 5) injected with Fab labeled using HPLC-purified [F-18]SFBS. Infarct:normal myocardium tissue uptake ratios for these animals were as high as 11.9:1; however, infarct:blood ratios at 2$3.5 \mathrm{hr}$ were only 1.0 to $1.6: 1$. Maximum target to non-target ratios were seen with antimyosin $\mathrm{F}\left(\mathrm{ab}^{\prime}\right)_{2}$. Using this fragment, infarct:normal myocardium ratios as high as $20.6: 1$ and infarct:blood ratios as high as 3.2:1 were achieved. In samples from normal myocardium, uptake in endocardium, mid-myocardium and epicardium were quite similar. In general, uptake in samples from the border and ischemic regions was highest in the endocardium and lowest in the epicardium. These results demonstrate that preferential uptake of F-18 labeled antimyosin $\mathrm{MAb}$ fragments in infarcted myocardium can be achieved as early as $2 \mathrm{hr}$ after injection.

In the PET scans performed on Dogs 2-5, there was a suggestion of increased accumulation of F-18 activity in regions of the myocardium expected to be at risk in this model. Delineation of areas of infarcted tissue was complicated by the presence of high levels of F-18 activity in the blood pool. In the last dog studied, [N-13] ammonia perfusion images were acquired prior to injection of F-18 labeled antimyosin Fab in order to better define regions with compromised perfusion. Using the [N-13]ammonia perfusion and reperfusion images, regions of interest were set; regions $9,10,11$ had relatively high uptake and were considered to represent normal myocardium and regions 3,4 , and 5 had the lowest activity levels and were considered to contain infarcted tissue. In Figure 6, the uptake of F-18-labeled Fab in these regions of interest is plotted as a function of time. Infarct:normal myocardium uptake ratios calculated from these images increased from 1.5:1 at $1 \mathrm{hr}$ to $4.0: 1$ at $4 \mathrm{hr}$. These preliminary results suggest that F-18 labeled antimyosin MAb fragments may be useful for imaging damaged myocardium; however, some form of blood pool subtraction probably will be required.

Distribution of ${ }^{18} F$-labeled Me1-14 F(ab') ${ }_{2}$ in normal dogs. Labeled MAb tissue distribution in mice often is not predictive of that seen in humans, particularly with regard to rates of normal tissue clearance. For this reason, we next investigated the pharmacokinetics of ${ }^{18} \mathrm{~F}$-labeled Me1-14 $\mathrm{F}\left(\mathrm{ab}^{\prime}\right)_{2}$ in normal dogs. A relatively large breed, the foxhound, was studied because their weight $(30-35 \mathrm{~kg}$ ) and size more closely approximate those of humans, and facilitate PET imaging. One group of 4 animals received ${ }^{18} \mathrm{~F}$-labeled Me1-14 $\mathrm{F}(\mathrm{ab})_{2}$, prepared using SFBS (1.0-4.0 mCi, 1 $\mathrm{mg}$ ) and the other group, Me1-14 F(ab') labeled using SFB (1.5-3.2 $\mathrm{mCi}, 1 \mathrm{mg}$ ). PET images of $20 \mathrm{~min}$ duration were acquired at two bed positions during the course of the study. Serial blood samples were obtained for $4 \mathrm{hr}$ after injection, at which time the animals were euthanized and tissue samples obtained for counting of ${ }^{18} \mathrm{~F}$ activity.

Statistical moment methods were used to perform nonparametric pharmacokinetic analyses for ${ }^{18} \mathrm{~F}$ blood pool activity. Area under the curve (AUC), mean residence time (MRT), total body clearance $\left(\mathrm{Cl}_{\mathrm{tb}}\right)$, apparent volume of distribution at steady state $\left(\mathrm{Vd}_{\mathrm{ss}}\right)$, and elimination half life 
$\left(T_{1 / 2}\right)$ were calculated. For the data collected during the 4-hr experimental period, no significant differences were observed between the SFBS and SFB groups with regard to AUC, MRT, Vd, $\mathrm{Cl}_{\mathrm{tb}}$ and $\mathrm{T}_{1 / 2}$, However, when the serum clearance curve was extrapolated to zero using the terminal elimination half life, serum AUC, MRT and $T_{1 / 2}$ were significantly higher with SFBS, suggesting slower clearance of activity when this labeling method was used. Urine could be collected from male animals and a larger \% ID was recovered from dogs receiving $\mathrm{F}(\mathrm{ab})_{2}$ labeled using SFB ( 0.3 and $3.0 \%$ vs. 6.2 and $11 \%)$. Based on the tissue uptake levels determined by PET imaging and at necropsy, radiation absorbed dose calculations were performed for a hypothetical $10 \mathrm{mCi}$ dose of ${ }^{18} \mathrm{~F}$-labeled Me1-14 $\mathrm{F}\left(\mathrm{ab}^{\prime}\right)_{2}$. The critical organ with SFBS was the spleen (4.15 $\mathrm{rad}$ ) while with SFB, the critical organ was the kidney (4.56 rad). These results suggest that it would be feasible to administer a $10 \mathrm{mCi}$ dose of ${ }^{18} \mathrm{~F}$-labeled Me1-14 $\mathrm{F}\left(\mathrm{ab}^{\prime}\right)_{2}$ to humans.

The tissue distribution of ${ }^{18} \mathrm{~F}$-labeled Me1-14 $\mathrm{F}\left(\mathrm{ab}^{\prime}\right)_{2}$ measured in the dog was compared with that determined previously in athymic mice. No significant differences were observed between the two species in kidneys and liver with the SFBS method. In contrast, lung and spleen levels were significantly higher in dogs than mice. A contributory factor appears to be the nearly 4-fold higher levels of ${ }^{18} \mathrm{~F}$ found in the blood of dogs compared with mice. Similar differences between species were seen with SFB.

The feasibility of tumor imaging with ${ }^{18} \mathrm{~F}$-labeled $\mathrm{F}\left(\mathrm{ab}^{\prime}\right)_{2}$ can be predicted by comparing the canine normal tissue uptake data with the tumor uptake observed in patients with ${ }^{131}$ I-labeled Me1$14 \mathrm{~F}\left(\mathrm{ab}^{\prime}\right)_{2}\left(1-5 \times 10^{-3} \% \mathrm{ID} / \mathrm{g}\right)$. Since these dogs weighed about $35 \mathrm{~kg}$, a rough estimate of normal tissue uptake in $70 \mathrm{~kg}$ humans was made by dividing the \% ID/g measured in the dog by 2 . For kidneys, liver, spleen, and lungs, tumor-to-normal tissue ratios less than 1 were estimated, suggesting that imaging tumors in these organs with ${ }^{18} \mathrm{~F}$-labeled $\mathrm{F}\left(\mathrm{ab}^{\prime}\right)_{2}$ would not be feasible during the first $4 \mathrm{hr}$ after injection. In patients, brain tumors could be imaged with ${ }^{131}$ I-labeled Me1-14 $\mathrm{F}\left(\mathrm{ab}^{\prime}\right)_{2}$ at $6 \mathrm{hr}$. Thus, with its low normal brain uptake, ${ }^{18} \mathrm{~F}$-labeled Mel-14 $\mathrm{F}\left(\mathrm{ab}^{\prime}\right)_{2}$ might be useful for PET imaging of gliomas. It is difficult to predict whether tumor imaging at other anatomical locations would be possible; however, the tomographic nature of PET should allow tumor detection in the presence of higher normal tissue background levels than possible with conventional imaging techniques. Moreover, as discussed in the following section, ${ }^{18} \mathrm{~F}$ labeling of smaller $\mathrm{MAb}$ fragments such as Fab may be a more feasible approach.

PET imaging of osteosarcoma in dogs using ${ }^{18} \mathrm{~F}$-labeled TP-3 Fab. We have evaluated the feasibility of PET tumor imaging with ${ }^{18} \mathrm{~F}$-labeled MAb fragments in dogs with primary and metastatic osteosarcomas. The Fab fragment of murine TP-3, an $\operatorname{IgG}_{2 b}$, was used. This MAb was selected because it reacts with both human and canine osteosarcomas. Labeling was performed by the SFBS method. Coupling efficiencies were three- to fivefold lower than seen when SFBS was reacted with other MAbs, and when TP-3 Fab was labeled with SIB. While the reason for the reduced SFBS coupling yields with TP-3 Fab is not known, a likely possibility is that the 8-carbon spacer between the active ester and the aryl fluoride in SFBS may interfere with reactivity with the lysines on the MAb. 
Four dogs with histologically confirmed osteosarcoma (1 primary, 3 metastatic, with 2 dogs studied twice) were evaluated by serial PET imaging and pharmacokinetic analysis. Blood clearance of ${ }^{18} \mathrm{~F}$ activity was biphasic in all animals, albeit with a highly variable elimination half time ranging from 2 to $13 \mathrm{hr}$. Protein-associated activity in the serum, determined by trichloroacetic acid precipitation, decreased from more than $90 \%$ immediately after injection to $60-80 \%$ at $4 \mathrm{hr}$. This degree of catabolism of label is similar to that reported by other investigators for radioiodinated Fab fragments.

In the one dog with primary disease, PET imaging clearly demonstrated accumulation of ${ }^{18} \mathrm{~F}$ activity at the tumor site as early as $15 \mathrm{~min}$ after injection. Biopsies obtained from this animal after euthanasia indicated tumor uptake of (1-3) $\times 10^{-3} \% \mathrm{ID} / \mathrm{g}$. In the dogs with metastatic disease, PET images at early time points largely reflected blood pool activity, while at later times, uptake in suspected metastatic sites was observed. Using a region of interest set over this tumor, an uptake of (2-4) $\times 10^{-3} \% \mathrm{ID} / \mathrm{g}$ was calculated. The levels of tumor accumulation of ${ }^{18} \mathrm{~F}$-labeled TP-3 Fab measured in these dogs were similar to those reported in most clinical studies using Fab fragments, suggesting the potential value of dogs with spontaneous tumors for the preclinical evaluation of labeled MAbs.

\section{Fluorine-18 Labeled MIBG Analogues}

Para- and meta- $\left.\right|^{18}$ Flfluorobenzylguanidine. MIBG has been used for the evaluation of neuroendocrine tumors such as neuroblastoma and carcinoid, and abnormalities in cardiac innervation. We have synthesized meta $-\left[{ }^{18} \mathrm{~F}\right]$ fluorobenzylguanidine (MFBG) and para$\left[{ }^{18} \mathrm{~F}\right]$ fluorobenzylguandine (PFBG) and evaluated their potential as MIBG analogues for PET imaging. Tetrabutylammonium $\left[{ }^{18} \mathrm{~F}\right]$ fluoride was reacted with 4- or 3-nitrobenzonitrile to form $\left[{ }^{18} \mathrm{~F}\right]$ fluorobenzonitrile by fluoro for nitro exchange. The product was then reduced with lithium aluminum hydride to yield $\left[{ }^{18} \mathrm{~F}\right]$ fluorobenzylamine. This compound was reacted with 2-methyl-2thiopseudourea at $130^{\circ} \mathrm{C}$ to yield PFBG or MFBG. As expected, overall radiochemical yields for MFBG (10-15\%) were considerably lower than those for PFBG (50-55\%) because of the difficulties in performing the fluoro for nitro exchange reaction with the meta isomer. PFBG also was synthesized from 4-nitrophenyl trimethylammonium trifluoromethanesulfonate (QS).

To evaluate the effect of fluorine for iodine substitution in MIBG on its specificity, in vitro binding to human neuroblastoma SK-N-SH uptake-1 positive and SK-N-MC negative control cell lines was measured. Nonspecific binding was $2 \%$ or less for PFBG, MFBG and MIBG. Net specific binding was $55.4 \pm 0.5 \%$ for MIBG, $34.5 \pm 3.5 \%$ for MFBG, $26.5 \pm 1.1 \%$ for PFBG using QS, and $16.9 \pm 1.6 \%$ for PFBG using the nitro precursor. Thus, MFBG and PFBG exhibit specific binding to human neuroblastoma cells, but at a lower level than seen with MIBG. Although heart uptake in mice of PFBG prepared using QS at $4 \mathrm{hr}$ was lower than that observed with MIBG, we have demonstrated excellent myocardial uptake of PFBG in normal dogs. The distribution of PFBG has also been studied in a dog with pheochromocytoma, a tumor known to accumulate MIBG in humans. Intense uptake of activity was seen in a region corresponding to the known tumor site and tumor-tolung and tumor-to-liver ratios calculated from the $30 \mathrm{~min}$ PET scan were $28: 1$ and 17:1, respectively. 
4-[18F]Fluoro-3-iodobenzylguanidine (FIBG). As noted above, specific binding to neuroblastoma cells in vitro and myocardial uptake in mice of PFBG and MFBG were significantly lower than observed for MIBG in parallel studies. We hypothesized that this behavior could be related to the lower lipophilicity of MFBG and PFBG due to the absence of iodine in their structures. This motivated our studies with FIBG, an analogue which should have a similar lipophilicity to MIBG. A four-step radiosynthesis of FIBG has been developed. Briefly, 4-cyano-2-iodo- $(N, N, N-$ trimethyl)anilinium trifluoromethanesulfonate was radiofluorinated using $\left[{ }^{18} \mathrm{~F}\right] \mathrm{KF}$ and $\mathrm{Kryptofix}{ }^{\circledR}$ in DMSO. The 4- $\left[{ }^{18} \mathrm{~F}\right]$ fluoro-3-iodobenzonitrile thus obtained was reduced using $\mathrm{NaBH}_{4} / \mathrm{T}_{2}$ to 4 $\left[{ }^{18}\right.$ F]fluoro-3-iodobenzylamine. This intermediate was converted to FIBG, first by treating it with $N, N^{\prime}$-(di-tert-butylcarbonyl)thiourea in the presence of mercuric chloride and triethylamine in DMF, and then deprotecting with trifluoroacetic acid. The final product, obtained in $5 \%$ decay-corrected yield, was purified by reverse-phase HPLC.

The in vitro binding properties of FIBG were compared in paired-label format to no-carrieradded [ ${ }^{125}$ T]MIBG. Binding of FIBG to SK-N-SH neuroblastoma cells remained constant (77-83\%) through a 2-3 $\log$ dose range and was significantly higher than that observed for MIBG (67-71\%, $P$ $<0.05$ ). In order to determine whether accumulation of FIBG occurs via the uptake-1 mechanism, its binding was measured in the presence of the uptake-1 inhibitors desipramine and norepinephrine, as well as carrier FIBG and MIBG. In all cases, binding of FIBG to SK-N-SH cells was reduced to $10 \%$ or less of control levels. The energy dependent nature of FIBG uptake was confirmed by the reduction in its cell binding at $4^{\circ} \mathrm{C}$ and in the presence of ouabain. In a preliminary study, we have observed that the specific binding of $\left[{ }^{131} \mathrm{I}\right] \mathrm{FIBG}$ to SK-N-SH neuroblastoma cells in vitro is higher than that of no-carrier-added $\left[{ }^{131} \mathrm{I}\right] \mathrm{MIBG}$. Thus, $\left[{ }^{18} \mathrm{~F}\right] \mathrm{FIBG}$ might be of particular value for determining dosimetry prior to a therapy study with $\left[{ }^{131} \mathrm{I}\right] \mathrm{FIBG}$.

\section{Labeling of a Chemotactic Peptide with ${ }^{18} \mathrm{~F}$}

The feasibility of imaging bacterial infection with radiolabeled chemotactic peptides has been demonstrated in recent studies by the Massachusetts General Hospital group. If a chemotactic peptide could be labeled with ${ }^{18} \mathrm{~F}$, then it might be possible to exploit the advantages inherent to PET for imaging infection. To explore this possibility, we have adapted the SFB method for labeling the chemotactic peptide $\quad N$-formyl-norleucyl-leucyl-phenylalanyl-norleucyl-tyrosyl-lysine (FNleLFNleYK) with ${ }^{18} \mathrm{~F}$.

To provide cold compound for use as an HPLC standard and in the binding studies, FNleLFNleYK was reacted with a fivefold molar excess of SFB for $4-5 \mathrm{hr}$ at room temperature. The resultant FNleLFNleYK-SFB conjugate was purified by HPLC and its composition confirmed by amino acid analysis. For labeling with ${ }^{18} \mathrm{~F}$, SFB was prepared and purified according to our revised method. HPLC solvent was removed from the SFB fractions, the activity was dried in the bottom of a Reacti ${ }^{\circledR}$ vial, and $1 \mu \mathrm{L}$ of triethylamine and $5 \mu \mathrm{L}$ of $50 \mathrm{mM}$ FNleLFNleYK in DMF were added. Addition of a small crystal of $\mathrm{LiCl}$ facilitated solubilization of the peptide. After a 5 min reaction at room temperature, purification of the labeled peptide conjugate was accomplished using reversephase HPLC. This system was effective in removing unlabeled peptide from the FNleLFNleYK-SFB 
conjugate. Between 10 and $15 \mathrm{mCi}$ of labeled peptide could be obtained from $100 \mathrm{mCi}$ of $\left[{ }^{18}\right.$ F]fluoride in a total synthesis time of $100 \mathrm{~min}$.

The coupling efficiency of SFB to peptide was $80 \%$ compared with about $60 \%$ when this reagent was reacted with MAbs. The higher conjugation efficiency with peptide could be related to the fact that the reaction was carried out in a homogeneous DMF solution. With MAbs, an aqueous buffer is used and limited solubility of SFB in aqueous solutions and competitive hydrolysis of SFB are two factors which could contribute to decreased coupling yields under these conditions. In addition, conjugation efficiency increases at higher $\mathrm{pH}$ because a higher proportion of lysine $\epsilon$-amino groups are available for reaction. But with MAbs, a pH above 8.5 may not be advisable because of concerns about protein denaturation. These results are encouraging since they demonstrate that SFB can be adapted for labeling peptides with ${ }^{18} \mathrm{~F}$.

The effect of SFB conjugation on the potency of FNleLFNleYK was investigated in a competitive binding assay to human polymorphonuclear leukocytes (PMN) using the prototypical ligand $\left[{ }^{3} \mathrm{H}\right] \mathrm{FMLF}$. The FNleLFNleYK-SFB conjugate had an $\mathrm{IC}_{50}$ of $40-50 \mathrm{nM}$ compared with 10$12 \mathrm{nM}$ for FNleLFNleYK, suggesting a reduction in binding affinity due to SFB coupling. However, SFB conjugation did not effect biological activity. The $\mathrm{IC}_{50}$ values for superoxide production of FNleLFNleYK and its FNleLFNleYK-SFB conjugate were both in the range of 2-4 nM, compared with $28 \mathrm{nM}$ for FMLF. The ability of FNleLFNleYK- $\left.-{ }^{18} \mathrm{~F}\right] \mathrm{SFB}$ to bind to PMN in vitro also was determined. Binding with and without an excess of cold FNleLFNleYK-SFB was $80 \%$ and $5 \%$, respectively, indicating a specific binding of $75 \%$. The tissue distribution of FNleLFNleYK$\left[{ }^{18} \mathrm{~F}\right] \mathrm{SFB}$ was evaluated in normal mice. Activity cleared from the blood with a half time of about $20 \mathrm{~min}$ and rapid excretion via the kidneys was seen. Retention of activity in the gastrointestinal tract was also noted, possibly reflecting the lipophilicity of FNleLFNleYK- $\left[{ }^{18} \mathrm{~F}\right] \mathrm{SFB}$. This suggests that developing less lipophilic SFB analogues could be an important direction for future research.

\section{Location of Lysine Residues in TP-1 and TP-3 Monoclonal Antibodies: Implications for Radiolabeling}

We have been working with Dr. Inger Sandlie, Department of Molecular and Cell Biology, University of Oslo, on the use of DNA recombinant technology to provide information about the number, position and accessibility of lysines in MAbs of potential interest for radioimmunotherapy. These studies have focused on TP-1 and TP-3, two MAbs reactive with different epitomes expressed on both human and canine osteosarcomas. These MAbs were selected not only because of their potential clinical value but also because a knowledge of their lysine configuration provides unique background information for interpretation of studies, such as those proposed in this application, investigating radiolabeled TP-1 and TP-3.

The V genes of TP- 1 and TP-3 MAbs were cloned and sequenced. The V gene sequences were

analyzed by a computer program to confirm that they were $\mathrm{V}$ gene segments and then were translated into amino acids using the same program. On the basis of the amino acid sequence, the framework regions (FR) and the complementary determining regions (CDRs) which contain the antigen binding 
site, were identified. Comparisons to known sequences revealed that the TP- $1 V_{L}$ and TP-3 $V_{L}$ chain sequences belonged to the $V_{\kappa} V I$ and $V_{K}$ III subgroups, respectively, whereas the TP-1 $V_{H}$ and TP-3 $V_{H}$ chain sequences belonged to the $V_{H}$ subgroups I(A) and II(A), respectively.

Examination of the TP variable regions reveals that TP-1 and TP- 3 contain a total of 12 and 14 lysines, respectively. Although the majority of the lysines are within the conserved framework, some, indicated in bold in Table 2, are present in the CDRs. The positions of the lysines with regard to the folding of the domain and interdomain interactions were analyzed in an attempt to illuminate their accessibility for labeling. Also, a prediction of whether labeling the lysine residues present in CDRs will interfere with antigen binding was made. In the absence of crystallographic data, models were obtained by comparing the TP sequences with solved crystal structures obtained from the Brookhaven and Leeds crystallographic databases. Analyses of the variable region light chain data are summarized below.

Initial inspection of the space filling models suggests that all the lysines in both $V_{L}$ chains would be accessible for labeling; however, Lys $^{45}$ has been reported buried $V_{L}-V_{H}$ interfaces in some molecules. A comparison of the residues on either side of $\mathrm{Lys}^{45}$ in both TP- $\mathrm{V}_{\mathrm{L}}$ chains was therefore made, and identical residues were found in molecules in which the residue at position 45 was not buried. Thus, we assume that $\mathrm{Lys}^{45}$ is exposed, as suggested by the space filling models. In the TP- $1 \mathrm{~V}_{\mathrm{L}}$ sequence, $\mathrm{Lys}^{53}$ is within the CDR2. According to the canonical structure model, the residue at position 53 is hydrogen-bonded to residue 49 so that the $\mathrm{L} 2$ region becomes a three residue hairpin loop (residues 50 to 52). The CDR2 regions of HyHel-5 and TP-1 are identical and $\mathrm{Lys}^{53}$ in HyHel-5 is reported to be mostly exposed, neither in contact with its antigen nor the opposite domain. The space filling model for the TP- $3 \mathrm{~V}_{\mathrm{L}}$ shows the lysine located in the CDR1 at position 27. This $\mathrm{Lys}^{27}$ is within $\mathrm{L} 1$ and according to the literature, residues at this position are completely exposed.

The size of the labeled molecule conjugated to lysines should influence its effect on antigen binding because a large molecule may obstruct a tight fit between the residues directly involved in binding. Therefore, labeling of $\mathrm{Lys}^{53}$ and $\mathrm{Lys}^{27}$ may obstruct antigen binding even if the residues are not part of the actual binding site. As an approach for dealing with this potential problem, the possibility of substitution of another amino acid for $\mathrm{Lys}^{27}$ could be considered. With this goal in mind, we compared the residues present on either sides of these lysines with other sequences and sequences with a glutamine at position 27 were found. The overall domain structure and also the local canonical structure of $L 1$ will therefore probably be conserved if $L y s^{27}$ were exchanged with glutamine. Thus, if labeling at this position compromised antigen binding, substitution of a glutamine for the lysine at position 27 could be made.

\section{Tumor localized hyperthermia}

One approach for increasing the rate and magnitude of MAb delivery to tumor is local hyperthermia. If effective, hyperthermia could be particularly valuable for use with shorter-lived nuclides. We have been investigating the effects of tumor-localized hyperthermia on the tissue 
distribution of Me1-14 F(ab') $)_{2}$ and RPC 5 control fragment in athymic mice bearing D-54 MG human glioma xenografts on one leg. In our initial study, we demonstrated that heating the tumorbearing leg at $42^{\circ} \mathrm{C}$ increased tumor uptake and tumor-to-normal tissue ratios of both fragments by two- to threefold compared to controls maintained at $37^{\circ} \mathrm{C}$. In a second study, the effects of tumorlocalized hyperthermia at $37^{\circ} \mathrm{C}, 40^{\circ} \mathrm{C}, 42^{\circ} \mathrm{C}$ and $44^{\circ} \mathrm{C}$ were compared in order to determine the temperature optimum for this procedure. Unlike the first set of experiments where anesthesia was used, animals were immobilized during heating using individual plastic restrainers. Groups were heated for $4 \mathrm{hr}$ and then euthanized immediately or $12 \mathrm{hr}$ later. The results indicate that increased uptake of specific MAb is not augmented by hyperthermia until temperatures of $42^{\circ} \mathrm{C}$ are reached. The $44^{\circ} \mathrm{C}$ group exhibited the highest tumor uptake at $4 \mathrm{hr}$; however, $12 \mathrm{hr}$ later, no significant differences were seen among the $37^{\circ} \mathrm{C}, 40^{\circ} \mathrm{C}$ and $44^{\circ} \mathrm{C}$ groups. Animals heated to $44^{\circ}$ $\mathrm{C}$ showed signs of toxicity with several deaths at $12 \mathrm{hr}$, consistent with reports that temperatures above $43^{\circ} \mathrm{C}$ are cytotoxic and result in vessel thrombosis. These results were consistent with those that might be expected based on the known effects of heating on tumor hemodynamics, and support our initial choice of $42^{\circ} \mathrm{C}$ for tumor-localized hyperthermia.

Our results suggest that tumor-localized hyperthermia may be able to augment the therapeutic efficacy of MAbs and fragments labeled with shortlived nuclides such as At-211. Certain aspects of this work can be pursued in athymic mouse models. However, baseline and post heating studies using PET in a larger animal will be critical for optimizing this approach. One reason is the effect of hyperthermia on apparent tumor size. For example, in the experiment illustrated in Figure 11, there were no significant differences in initial tumor size among the groups $\left(200 \pm 58 \mathrm{~mm}^{3}\right.$ to 217 $\pm 89 \mathrm{~mm}^{3}$ ). However, the average weight at dissection for tumors heated at or above $42^{\circ} \mathrm{C}$ was significantly higher than those at lower temperatures $(0.21 \pm 0.09 \mathrm{~g}$ versus $0.12 \pm 0.07 \mathrm{~g} ; \underline{\mathrm{P}}=0.002)$.

A subsequent experiment was performed to address this issue directly. At $37^{\circ} \mathrm{C}, 4 \mathrm{hr}$ heating did not change tumor volume (initial, $304 \pm 75 \mathrm{~mm}^{3} ; 4 \mathrm{hr}, 316 \mathrm{~mm}^{3}$ ) while at $42^{\circ} \mathrm{C}$, a twofold increase in volume occurred (initial, $298 \pm 70 \mathrm{~mm}^{3} ; 4 \mathrm{hr}, 660 \pm 176 \mathrm{~mm}^{3}$ ). This increase in tumor size and weight, presumably due to increased blood or edema, complicates the comparison of MAb uptake in different groups of mice on a \% $\mathrm{ID} / \mathrm{g}$ basis. This is the type of problem that could be circumvented by using PET to determine the tumor uptake of MAb in the same animal before and after hyperthermia.

\section{TRAINING}

No graduate program exists in Radiology, the department in which the principal investigator holds his primary appointment. However, James Schuster received his Ph.D. in Pathology in 1992 for work funded in part by this grant. Michael Noska was a Department of Energy Occupational Health Physics Fellow in the Department of Environmental Science and Engineering at the University of North Carolina and received his Masters Degree for work related to this grant and performed in the laboratory of the principal investigator. Finally, Marlene Hauck, D.V.M., is a doctoral student in the University Program in Cell and Molecular Biology at Duke. Her thesis 
project is directly related to this grant.

\section{E. PUBLICATIONS}

\section{Peer-Reviewed Journal Articles Supported Fully or Mainly by this Grant}

1. Cope, D.A., Dewhirst, M.W., Friedman, H.S., Bigner, D.D., and Zalutsky, M.R.: Enhanced delivery of a monoclonal antibody $\mathrm{F}\left(\mathrm{ab}^{\prime}\right)_{2}$ fragment to subcutaneous human glioma xenografts using local hyperthermia. Cancer Res. 1990; 50:1803-1809.

2. Garg, P.K., Garg, S., and Zalutsky, M.R.: Fluorine-18 labeling of monocional antibodies and fragments with preservation of immunoreactivity. Bioconjugate Chem. 1991; 2:44-49.

3. Zalutsky, M.R., Garg, P.K., and Narula, A.S.: Labeling monoclonal antibodies with halogen nuclides. Acta Radiol. Supp. 1990; 374:141-145.

4. Vaidyanathan, G., and Zalutsky, M.R.: Labeling proteins with fluorine-18 using $N$ succinimidyl 4-[ ${ }^{18}$ F]fluorobenzoate. Nucl. Med. Biol. 1992; 19:275-282.

5. Zalutsky, M.R., Garg, P.K., Johnson, S.H., and Coleman, R.E.: Fluorine-18 antimyosin monoclonal antibody fragments: preliminary investigation in a canine myocardial infarct model. J. Nucl. Med. 1992; 33:575-580.

6. Vaidyanathan, G., Bigner, D.D., and Zalutsky, M.R.: Fluorine-18-labeled monoclonal antibody fragments: a potential approach for combining radioimmunoscintigraphy and positron emission tomography. J. Nucl. Med. 1992; 33:1535-1541.

7. Garg, P.K., Garg, S., Bigner, D.D., and Zalutsky, M.R.: Localization of fluorine-18-labeled Mel-14 monoclonal antibody $\mathrm{F}\left(\mathrm{ab}^{\prime}\right)_{2}$ fragment in a subcutaneous xenograft model. Cancer Res. 1992; 52:5054-5060.

8. Garg, P.K., Garg, S., and Zalutsky, M.R.: Synthesis and preliminary evaluation of para- and meta- $\left[{ }^{18}\right.$ F $]$ fluorobenzylguanidine. Nucl. Med. Biol. 1994; 21:97-104.

9. Vaidyanathan, G., and Zalutsky, M.R.: An improved synthesis of $N$-succinimidyl 4$\left[{ }^{18} \mathrm{~F}\right]$ fluorobenzoate and its application to the labeling of a monoclonal antibody fragment. Bioconjugate Chem. 1994; 5:352-356.

10. Page, R.L., Garg, P.K., Garg, S., Archer, G.E., Bruland, Ø.S., and Zalutksy, M.R.: Positron emission tomographic imaging of osteosarcoma in dogs using an ${ }^{18} \mathrm{~F}$-labeled monoclonal antibody Fab fragment. J. Nucl. Med. 1994; 35:1506-1513.

11. Vaidyanathan, G., Affleck, D.J., and Zalutsky, M.R.: 4- $\left[{ }^{18} \mathrm{~F}\right]$ fluoro-3-iodobenzylguanidine: 
a potential MIBG analog for positron emission tomography. J. Med. Chem. 1994; 37:36553662.

12. Page, R.L., Garg, P.K., Vaidyanathan, G., and Zalutsky, M.R.: Preclinical evaluation and PET imaging of ${ }^{18} \mathrm{~F}$-labeled Mel-14 F(ab') fragment in normal dogs. Nucl. Med. Biol. 1994; 21:911-919.

13. Schuster, J.M., Zalutsky, M.R., Noska, M.A., Dodge, R., Friedman, H.S., Bigner, D.D., and Dewhirst, M.W.: Hyperthermic modulation of radiolabeled antibody uptake in a human glioma xenograft and normal tissues. Int. J. Hyperthermia 1995; 11:59-72.

14. Vaidyanathan, G., Affleck, D.J., and Zalutsky, M.R.: Validation of 4- $\left[{ }^{18} \mathrm{~F}\right]$ fluoro-3iodobenzyl-guanidine as a positron-emitting analog of MIBG. J. Nucl. Med., 1995; 36:644650 .

15. Olafsen, T.,Bruland, Ø.S., Zalutsky, M.R., and Sandlie, I.: Cloning and sequencing of V genes from anti-osteosarcoma monoclonal antibodies TP-1 and TP-3: location of lysine residues and implications for radiolabeling. Nucl. Med. Biol. 1995; Nucl. Med. Biol. 1995; 22:765-772.

16. Vaidyanathan, G., and Zalutsky, M.R.: Fluorine-18 labeled chemotactic peptides: a potential approach for the PET imaging of bacterial infection. Nucl. Med. Biol., 1995; 22:759-764.

17. Olafsen, T., Bruland, Ø.S., Zalutsky, M.R., and Sandlie, I.: Abundant tyrosine residues in the antigen binding site in anti-osteosarcoma monoclonal antibodies TP-1 and TP-3: application to radiolabeling. Acta Oncologica 1996; 35:297-301.

18. Berry, C.R., Garg, P.K., DeGrado, T.R., Hellyer, P., Weber, W., Garg, S., Hansen, B., Zalutsky, M.R., and Coleman, R.E.: Para- $\left[{ }^{18}\right.$ F]fluorobenzylguanidine kinetics in a canine coronary artery occlusion model. J. Nucl. Cardiol., 1996; 3:119-129.

19. Berry, C.R., Garg, P.K., Zalutsky, M.R., Coleman, R.E., and DeGrado, T.R.: Uptake and retention kinetics of para- $\left[{ }^{18} \mathrm{~F}\right]$ fluorobenzylguanidine in the isolated rat heart. $\mathrm{J}$. Nucl. Med., 1996; 37:2011-2016.

\section{Peer-Reviewed Journal Articles Supported in Part by the Grant}

20. Vaidyanathan, G., and Zalutsky, M.R.: Protein radiohalogenation: observations on the design of $N$-succinimidyl ester acylation agents. Bioconjugate Chem. 1990; 1:269-273.

21. Garg, S., Garg, P.K., and Zalutsky, M.R.: N-Succinimidyl-5-(trialkylstannyl)-3-pyridine carboxylates: a new class of reagents for protein radioiodination. Bioconjugate Chem. 
$1991 ; 2: 50-56$.

22. Vaidyanathan, G., Affleck, D.J., and Zalutsky, M.R.: Radioiodination of proteins using $N$ succinimidyl 4-hydroxy-3-iodobenzoate. Bioconjugate Chem. 1993; 4:78-84.

23. Garg, P.K., Garg, S., and Zalutsky, M.R.: $N$-succinimidyl-4-methyl-3-(tri-nbutylstannyl)benzoate: synthesis, radioiodination and potential utility for the radioiodination of monoclonal antibodies. Nucl. Med. Biol. 1993; 20:379-388.

24. Garg, S., Garg, P.K., Zhao, X.-G., Friedman, H.S., Bigner, D.D., and Zalutsky, M.R.: Radioiodination of a monoclonal antibody using $N$-succinimidyl 5-iodo-3pyridinecarboxylate. Nucl. Med. Biol. 1993; 20:835-842.

25. Garg, P.K., Alston, K.L., and Zalutsky, M.R.: Catabolism of radioiodinated murine monoclonal antibody $\mathrm{F}\left(\mathrm{ab}^{\prime}\right)_{2}$ fragment labeled using $\mathrm{N}$-succinimidyl 3-iodobenzoate and iodogen methods. Bioconjugate Chem. 1995; 6:493-501.

\section{Book Chapters and Reviews Supported Fully or in Part by this Grant}

20. Zalutsky, M.R., Garg, P.K., Vaidyanathan, G., and Garg, S.: Methods for the radiohalogenation of antibodies. In: Applications of Enzyme Biotechnology. Kelly, J.W., and Baldwin, T.O., eds. Plenum Press, New York, 1991; 15-28.

21. Garg, P.K., Berry, C.R., Garg, S., DeGrado, T.R., and Zalutsky, M.R.: Para$\left[{ }^{18} \mathrm{~F}\right]$ fluorobenzyl-guanidine: further evaluation of a potential PET tracer in dogs. In: Proceedings of the XVI International Cancer Congress. Rao, R.S., Deo, M.G., and Sanghvi, L.D., eds. Monduzzi Editore, Bologna, Italy, 1994; 113-118.

22. Vaidyanathan, G., Affleck, D.J., Slade, S.A., Welsh, P., and Zalutsky, M.R.: No-carrieradded 4-fluoro-3-iodobenzylguanidine labeled with ${ }^{131} \mathrm{I}$ and ${ }^{18} \mathrm{~F}$ : potential MIBG analogues for PET imaging and therapy of neuroendocrine tumors. In: Proceedings of the XVI International Cancer Congress. Rao, R.S., Deo, M.G., and Sanghvi, L.D., eds. Monduzzi Editore, Bologna, Italy, 1994; 3013-1017.

23. Hauck, M.L., Dewhirst, M.W., and Zalutsky, M.R.: Local hyperthermia for enhancing the delivery of monoclonal antibodies. In: Targeted Delivery of Imaging Agents. Torchilin, V.P., ed., CRC Press, Boca Raton, FL, 1995; 335-361.

24. Zalutsky, M.R., Vaidyanathan, G., Garg, P.K., and Page, R.L.: Fluorine-18 labeled monoclonal antibodies for positron emission tomographic imaging. In: Targeted Delivery of Imaging Agents. Torchilin, V.P., ed., CRC Press, Boca Raton, FL, 1995; 665-691. 
25. Zalutsky, M.R., Schuster, J.M., Garg, P.K., Archer, Jr., G.E., Dewhirst, M.W., and Bigner, D.D.: Two approaches for enhancing radioimmunotherapy: alpha emitters and hyperthermia. In: Recent Results in Cancer Research: Systemic Radiotherapy with Monoclonal Antibodies. Sautter-Bihl, M.-L., Bihl, H., and Wannenmacher, M., eds. Springer, Berlin, 1996; 141:101-122.

26. Bast, R.C., Jr., Zalutsky, M.R., and Frankel, A.: Monoclonal Serotherapy. In: Cancer Medicine, 4th edition. Holland, J.F., Frei III, E., Bast, R.C., Jr., Kufe, D.W., Morton, D.L., and Weichselbaum, R.R., eds., Williams and Wilkins, Baltimore, 1996; 1245-1262.

27. Vaidyanathan, G., Affleck, D.J., Welch, P., Strickland, D.K., and Zalutsky, M.R.: Nocarrier-added MIBG and other halobenzylguanidines labeled with At-211 and F-18. In: Hormone and Metabolic Research. Thieme-Verlag, 1997; in press.

\section{DISCLAIMER}

This report was prepared as an account of work sponsored by an agency of the United States Government. Neither the United States Government nor any agency thereof, nor any of their employees, makes any warranty, express or implied, or assumes any legal liability or responsibility for the accuracy, completeness, or usefulness of any information, apparatus, product, or process disclosed, or represents that its use would not infringe privately owned rights. Reference herein to any specific commercial product, process, or service by trade name, trademark, manufacturer, or otherwise does not necessarily constitute or imply its endorsement, recommendation, or favoring by the United States Government or any agency thereof. The views and opinions of authors expressed herein do not necessarily state or reflect those of the United States Government or any agency thereof. 